\title{
Correction to: Moderate Treadmill Exercise Protects Synaptic Plasticity of the Dentate Gyrus and Related Signaling Cascade in a Rat Model of Alzheimer's Disease
}

\author{
An T. Dao ${ }^{1} \cdot$ Munder A. Zagaar ${ }^{1,2} \cdot$ Karim A. Alkadhi ${ }^{1}$
}

Published online: 5 October 2017

(C) Springer Science+Business Media, LLC 2017

Correction to: Mol Neurobiol (2015) 52(3): 1067-1076

https://doi.org/10.1007/s12035-014-8916-1

The original version of this article unfortunately does not include the second affiliating institution of Dr. Munder A. Zagaar. "Department of Pharmacy Practice and Clinical Health Sciences, Texas Southern University, Houston, TX 77004" should have been included on the paper.

With this, the authors hereby publish the complete affiliating institutions.

The online version of the original article can be found at https://doi.org/ 10.1007/s12035-014-8916-1

Karim A. Alkadhi

kalkadhi@uh.edu

1 Department of PPS, College of Pharmacy, University of Houston, Houston, TX 77204-5037, USA

2 Department of Pharmacy Practice and Clinical Health Sciences, Texas Southern University, Houston, TX 77004, USA 